\title{
AGRICULTURAL GRAPHICAL USER INTERFACE: AN ANDROID APPLICATION FOR THE FARMERS
}

\author{
Amrutanshu Panigrahi ${ }^{1}$, MdMohtabAlam² \\ ${ }^{1}$ Assistant Professor, Department of CSE, Netaji Subhas Institute of Technology, Bihar, India \\ ${ }^{2}$ Assistant Professor, Department of CSE, Netaji Subhas Institute of Technology, Bihar, India
}

\begin{abstract}
Since the introduction of Android in 2005, use of smart phones has been increased for past few years as it becomes the inevitable communication tool along with some more features for fun and entertainment. Some attributes like open platform, crosscompatibility and mesh up capability makes android operating system more elegant. In this paper our contribution is to develop a graphical based android application Agricultural Graphical User Interface (AGUI) for the agriculture, which can be easily used by anyone. Before cultivating the farmer needs to know some local characteristics about the crop like what amount of rain the crop actually needed, which type of soil is good for cultivating and also about the fertilizer needed by the crop. This application provides this basic information like environmental conditions, fertilizer information and also about the diseases and its corresponding remedy to the respective crops in graphical mode. The users need not to read anything for the use of this application.
\end{abstract}

Keywords: Android, Cross-compatibility, Mesh up capability, AGUI.

\section{INTRODUCTION}

An increasing number of smartphones and potential applications are forcing developers to overcome obstacles through the use of sound practices. The plight of a mobile application developer is a challenging one. The development in this current space is vibrant, since the spectrum of smart phone is redrawing the boundaries of what user can do. The initial android operation system was created by a small startup company in Silicon Valley known as Android Inc., which was purchased by Google in July 2005 [1]. The Open Handset Alliance released the Google Android SDK on November 12, 2007 [2]. Android is a software stack for mobile devices which includes an operating system and a software development environment. The android operating system is a Linux kernel based OS [6].

The conception of android has attracted the developers to the mobile communication field due to its some elegant features like open platform, cross-compatibility and mesh up capability. Open platform means android is not tied to one hardware manufacturer and one provider. It is open to all i.e. all hardware manufacturers and provider can make and sell android devices and the android source code is also having the open access. Cross-compatibility feature makes the android run in many devices regardless the screen size and resolution. Mesh up capability helps the developer to mesh two or more services to make one application [5].

In recent years mobile phones are not only used as the communication tools but also it is becoming the essential part of people's daily life as it is giving much more needed information along with so many fun and entertainment. Now the android system is becoming elegantly popular essentially in the smart phone market due to its features. Figure 1 shows the statistical representation of android mobile phone sells in different year. In 2007 the approximate number of android phones sold is 122.32 million. In 2008 this value increases about $13.87 \%$ and becomes 139.29 million. In 2011 the total number of android phone sell is approximately 472 million which is about $59.11 \%$ of 2010 . But in 2012, 2013, 2014 the total number increases about $44.07 \%, 105.44 \%$ and $163.75 \%$ of 2010 respectively. So the increment in the number of sell in recent years is in peak. This is all because of the attractive features and services of android operating system.

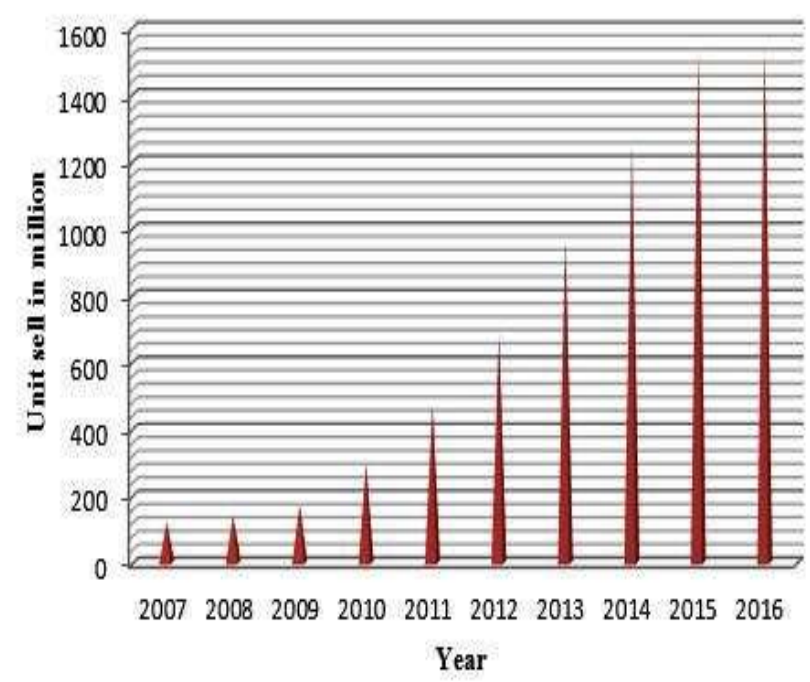

Fig 1: Statistical representation of android phone sells

In many developing countries, agriculture plays a major role in the country's economy. Therefore, agriculture sector must be strengthened to attain higher growth rates and to 
contribute to the economic development of the country [3]. So in this paper our research work is to develop an android application which will provide a farmer all local characteristics of the crop such as required environmental condition, fertilizers required and the diseases to corresponding crop. The texture of the application is totally based on the graphical view and in audio format i.e. all information provided by the application is in the form of image and the farmer can get the basic information about the crop in the form of audio.

The contextual information about what basic information required by the farmer is presented in the section II. The design of the application and all the requirements has been presented in the section III. Finally in section IV we have drawn our conclusion and future work.

\section{CONCEPTUAL INFORMATION}

In this paper our basic target is the farmers. By various study we are able to determine the local characteristic of the crop and the primary pre-cultivating and post-cultivating information needed by the farmer. The contextual information required by the farmer can be classified into 2 types, static information which changes very slowly with respect to time i.e. the environmental condition, fertilizers, diseases etc while the dynamic information consists of rapid change in the needed information i.e. marketing or selling of the crops. In this research work we have considered the statics information only for now. Later on we will consider about the dynamic information in this application. So the static information needed by the farmer is shown in table 1 .

Table -1: Name of the Table

\begin{tabular}{l} 
What type of soil needed for the cultivation of one crop? \\
What is the environmental condition needed to grow a \\
crop? \\
\hline What amount of water needed for cultivation? \\
\hline $\begin{array}{l}\text { What are the fertilizers required for the corresponding } \\
\text { crop? }\end{array}$ \\
\hline What are the possible diseases to the crop? \\
\hline What are symptoms for the corresponding disease? \\
\hline What are possible remedies to the diseases? \\
\hline What are symptoms for the corresponding disease? \\
\hline What are possible remedies to the diseases? \\
\hline
\end{tabular}

While giving the attention towards the above problems we need to consider few primary points such as types of farmer and the farm environment [3] into account. The farmers can be classified into garden farmers and the commercial farmers. The commercial farmers can be further classified into small scale farmer, medium scale farmer and high scale farmer based on types and amount of crops they are harvesting. The farm environment consists of location based environmental information of the farm i.e. rainfall, type of soil present, climate zone, temperature, sunlight and humidity of the location where the farmer wants to cultivate the crop.
In [4] author has grouped all the information needed by the farmer into 4 groups as pre-sowing, pre-harvest, postharvest and market information.But the challenges for the successful implementation of information into the mobile communication technology include institutional level, operational level and end user level challenges.

\section{DESIGN AND IMPLEMENTATION}

\subsection{Requirement Specification}

We have developed the application for android with the help of Eclipse platform. Eclipse is an integrated development environment which contains a workspace and an extensible plug in for customizing the environment written in java. It also can be used to develop java applications. Eclipse provides platform to develop android application with Android SDK module which includes java development tools. The all environmental setup for the application development is as follows:

- $\quad$ Android SDK tools revision 22.0.5

- $\quad$ SDK platform: Android 4.3 API 18: The minimum requirement for the android application development is Android 2.2 with API level 8. But it is the older version to develop the application. So we have taken the current version as the environmental variable. But it will not create any difficulty in compiling the application in the Android 2.2 version.

- $\quad$ Eclipse IDE: There is lots of eclipse version available which are compatible with Android SDK. In this work we have initially used Eclipse JUNO Package (version 4.2) and later on we have updated it to Luna Package (version 4.4.0).

- $\quad$ ADT for Eclipse: Android Developer Tools build v22.0.5-757759 is used for the current work. This product includes Eclipse Platform, JDT, CDT, EMF, GEF and WTP, all of which are Copyright (c) Eclipse contributors and others.

- $\quad$ AVD Manager provides the graphical UI which will act as a virtual android device for the compilation of the application file. To test and run the application the need of android device is must. So one can install the developed application in the emulator without any physical android devices. The emulator will emulate an android device in the computer. The facility provided by the android device will also be provided by the emulator but in the virtual manner.

\subsection{Design Approach}

For this android application there are 3 building blocks Activity, Intent Receiver, Content Provider. The Activity is a generally a single screen inside the application and is implemented as the single class which extends the base Activity class. Every specified class for each Activity provides a user interface to the application which will be consisting of several views, buttons etc, each of those having some event specified. This application consists of multiple screens. Moving to another screen intends to accomplish a new activity. When a new screen appears the older one is getting paused and put into a history stack, 
because when again the same user wants to come back to the previous screen then it is simply extracted back from the history stack. Android takes help of separate class Intent for the navigation between screens. The Intent explains what an activity will do. The Intent Receiver is used to execute the application in reaction to an external event. And the Content Provider is used to share the data between different applications. It is standard set of methods to let the other application share the data between applications.

While moving towards the design aspect of the application we have taken 6 different types of crops as rice, maize, wheat, red gram, black gram, green gram, peas, chickpeas and ground nut as sample for study. All the crops are shown in the application in the form of image. So the user need not to anything just by seeing the image it can confirm that about which crop it just want to know about. After confirmation it just clicks on any image which will take the user to another screen that will show the large image to the user for the better visual. In that screen user has two options. First option will suggest the user some information about the crop which will be in text format. If the user wants to know about the possible diseases regarding that crop then the second option will help the user to do so. In the list of disease screen the user will find all the diseases corresponding to the selected crop in an image view format. For confirmation user has to click any of the shown image, by doing so the user will be asked for the confirmation of the disease by showing the large image. After confirmation of the diseases user will have the remedy option for the selected disease. All data for the remedy of the diseases has been taken with the help of several studies from different agricultural department.All those remedies will be brought to user in the textual format. The user activity prospects are depicted in the UML diagrams such as USE case diagram, Activity diagram.

USE case diagram: We have designed Start Application, Crop List, Disease List, Disconnect use case for this application. The use case Start Application presents the launching of the application from the user device. The use case Crop List represents the list of sample crop taken as input for the application in an image format. The Disease List shows all possible diseases to one selected crop from the crop list by the user and also suggests the possible remedy for that disease. Finally the Disconnect use case is responsible for the closing the functionalities of the application after the tasks are done by the user prospect. The Table2-Table5 shows the use case description. Figure 2 shows the use case diagram for the application.

Activity Diagram: This activity diagram just indicates all the activities to be performed by the user while using the application. After starting the application the user will have the multiple choices to choose crop accordingly. After choosing the crop the application will show the entire possible disease list corresponding to that selected crop. Then the user has to select the disease as per own desire. After selecting the user will have the remedy list collected from various agriculture departments for the disease. Figure 3 shows the activity diagram designed for the application.

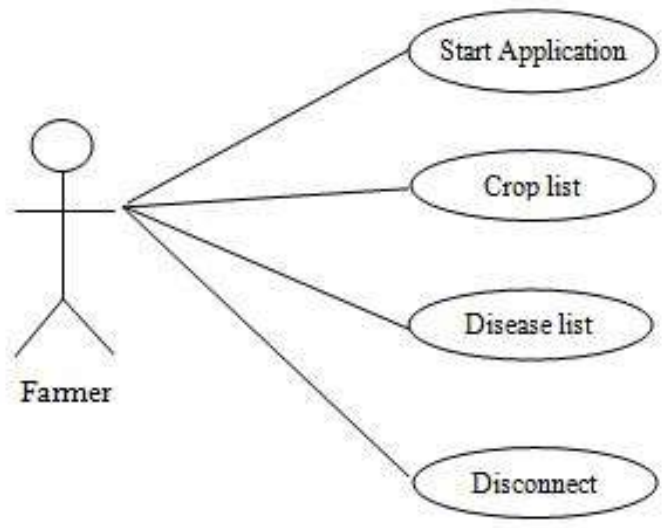

Fig2: USE Case diagram

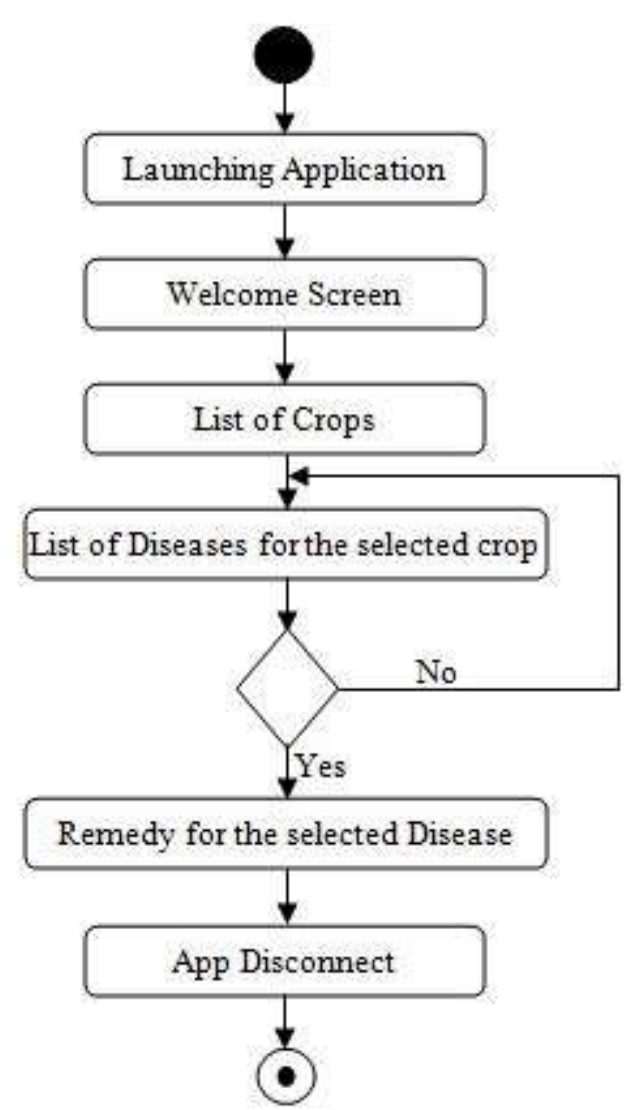

Fig3: Activity Diagram

Table 2: Start Application Use case

\begin{tabular}{|l|l|}
\hline Actor & User \\
\hline Pre-Condition & Android Device \\
\hline Description & Launches the application \\
\hline
\end{tabular}

Table 3: Crop list Use case

\begin{tabular}{|l|l|}
\hline Actor & User \\
\hline Pre-Condition & Application launched \\
\hline Description & All the crop list \\
\hline
\end{tabular}


Table 4: Disease list Use case

\begin{tabular}{|l|l|}
\hline Actor & User \\
\hline Pre-Condition & Corresponding crop selected \\
\hline Description & Disease and remedy regarding selected crop \\
\hline
\end{tabular}

Table 5: Disconnect Use case

\begin{tabular}{|l|l|}
\hline Actor & User \\
\hline Pre-Condition & Information completed \\
\hline Description & Exits the application \\
\hline
\end{tabular}

\subsubsection{Androidmanifest.xml File and its Usage}

The androidmanifest.xml file is responsible for the holding the important information used inside the application. All essential content of the application such as activities, content providers etc must be declared inside the androidmanifest.xml file. After creating the activity for the application it must be added to the androidmanifest.xml file in order to use the functionalities provided by that activity inside the application. It also declares some kinds of permission like camera access, bluetooth and internet access inside the application. Figure 4 show the snapshot for the android manifest file which has been used while designing our application.

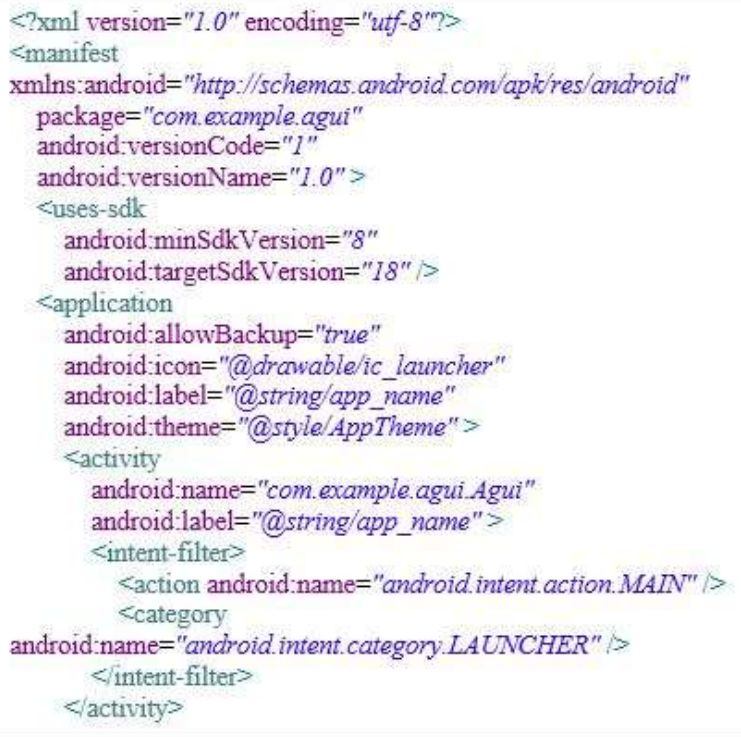

Fig4: Snapshot of androidmanifest.xml for the application

\subsection{Agricultural Graphical User Interface (AGUI)}

In this section we will describe the developed UI for the application. We have presented here some screen shots of the application. In this application we have taken 9 crops as the input. After launching the application the user will have the welcome screen. Fig 5 shows the snapshot for the welcome screen. In that activity the user only have one button which is used to navigate to the next activity. Fig 6 shows the next activity which brought in front of the user by clicking the button. It will show the crop lists in an image format. Initially we have included 9 crops as input. The user has to select any one of the crop among them. After successful selection the application will provide 2 options to the user such as the details for the crop and the corresponding diseases. When the user select the detail option then a text view containing some information regarding the crop but while selecting the disease option the user will have a new screen summarizing all the diseases in image format. By seeing the disease image the user has to select one of them. After selection the app will provide a new screen which contains the large image for the disease for better confirmation and also provides 2 more options such as detail and remedy. In detail option there will be the text view explaining the information regarding the disease and the remedy option will provide necessary action need to be taken in contrast. All those information has been collected by several surveys done from different agricultural departments.Fig7-Fig9 shows the confirmation page for rice, maize and wheat. But here for instance we have taken rice for only example. Fig 10 shows the detail information regarding the rice. Fig 11 shows the diseases list for the rice. We have selected bacterial blight disease for the rice. Fig 12 shows large image of bacterial blight with option, while selecting the detail option Fig 13 shows the details of bacterial blight and Fig 14 shows the possible remedy for the bacterial disease.

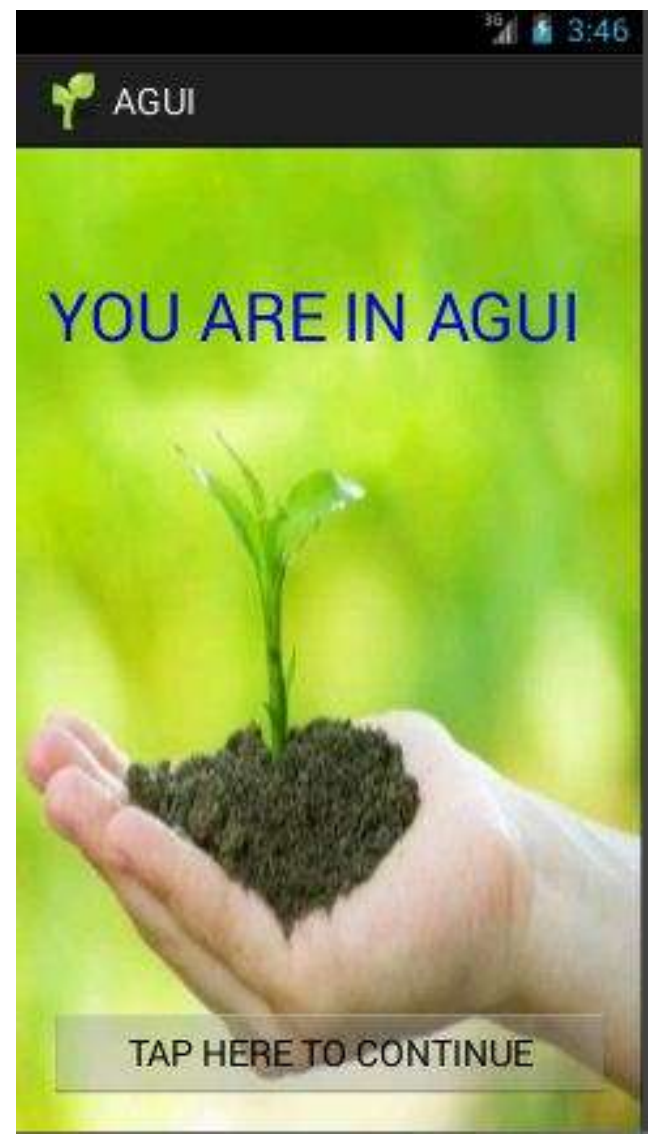

Fig5: Welcome Screen for AGUI 


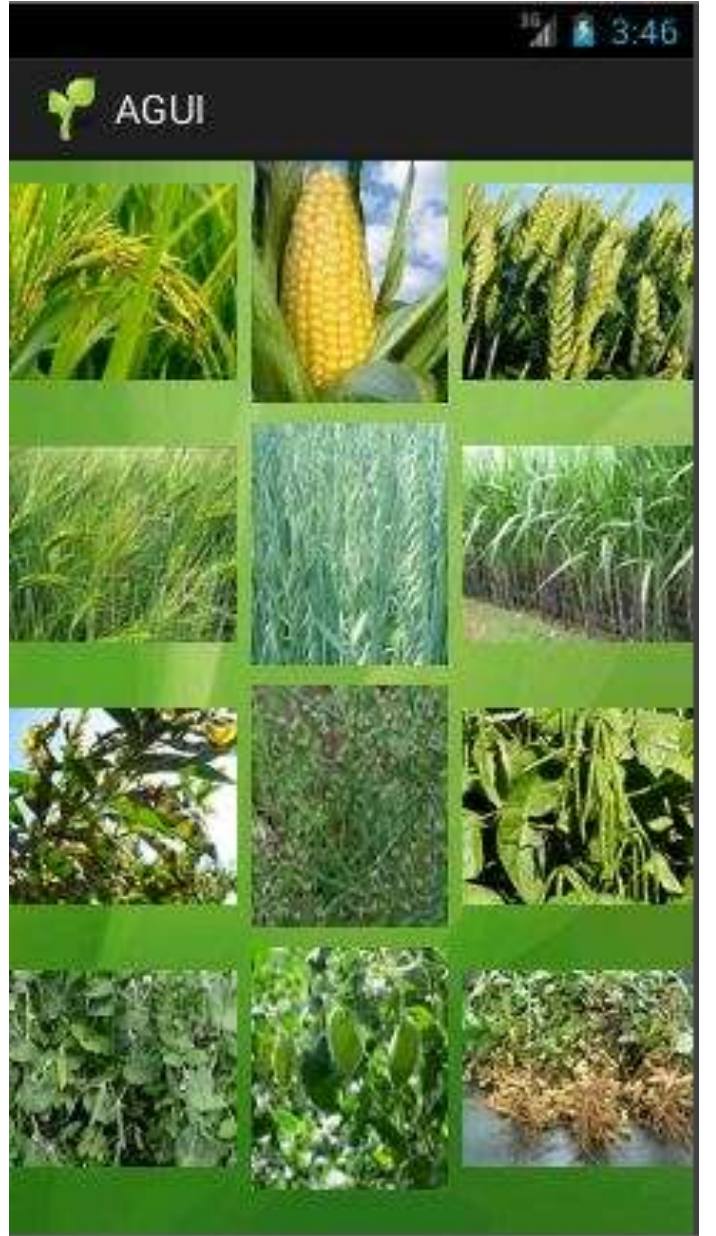

Fig 6: Crop list taken as input

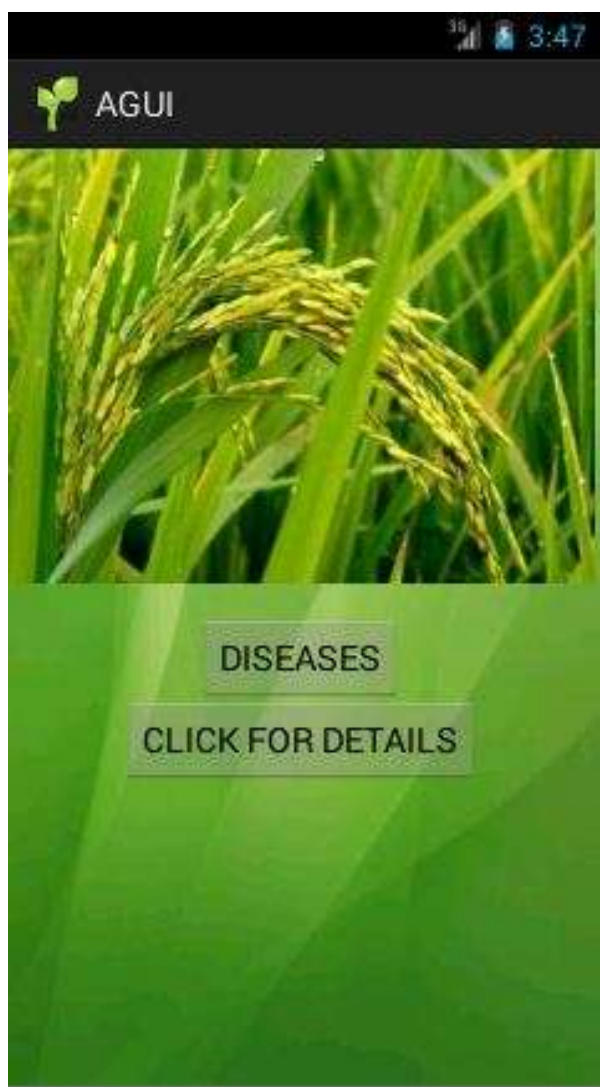

Fig 7: Confirmation for Rice

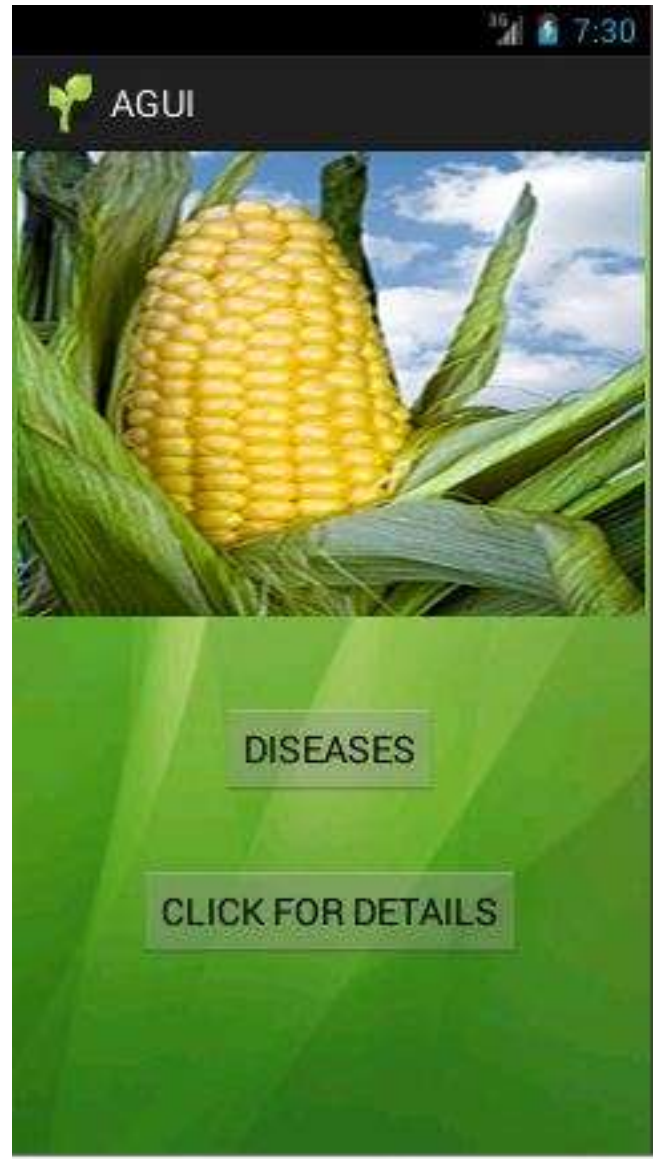

Fig 8: Confirmation for Maize

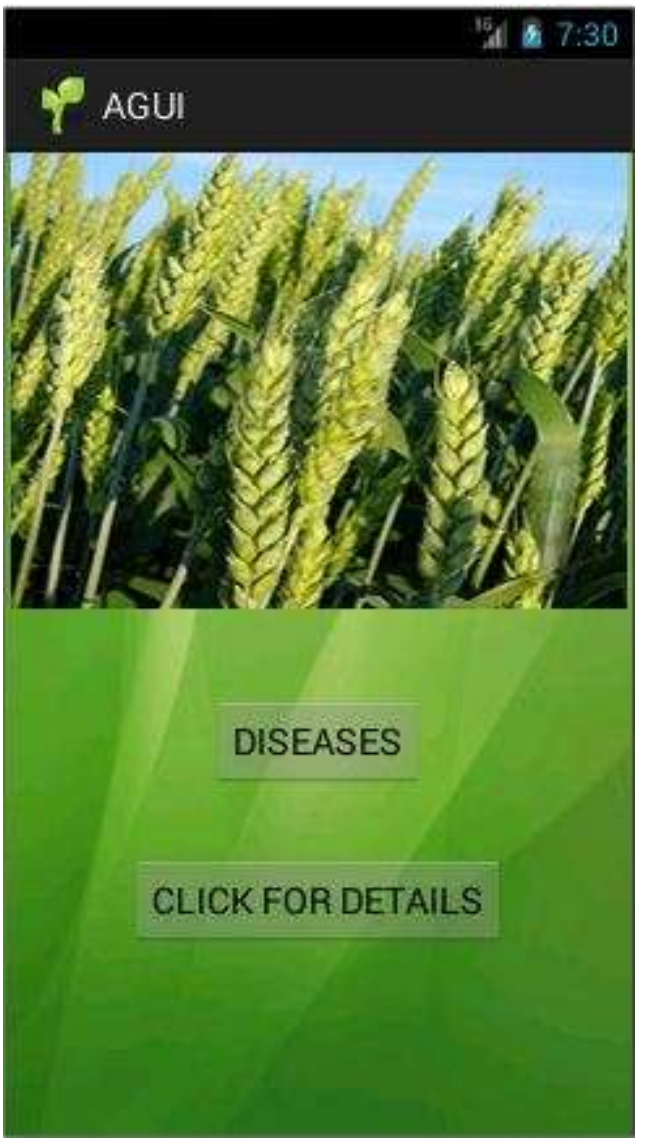

Fig 9: Confirmation for Wheat 


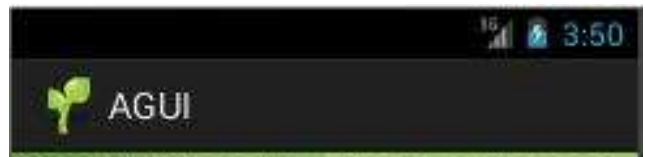

Rice cultivation is well-swied to countries and regions with low la bor costs ind high rainfall, 38 it is fabor-intensive to cultivate and renulres: ample water borrever pucean be grown practically anywhere, even on a steep fill or: mountain ares with the use of water-controlling terrace systems; Although it sparent species. are native to Asia and certain parts of Africa, centuries of trade and exportation have made it commonplace in many cultures worldwide. The traditional method for cultivating rice is flooding the fileds while, or after setting the young seedlings. This simple method requires sound planning and servicing of the water damming and channeling but reduces the growth of less robust weed and pest plants that have no submerged growth stats, and deters vermin. While flooding is not mandat ory for the cultivation of rice, all other methods of irrigation require higher effort in weed and pest control during growth periods and a different approach for fertilizing the soil:

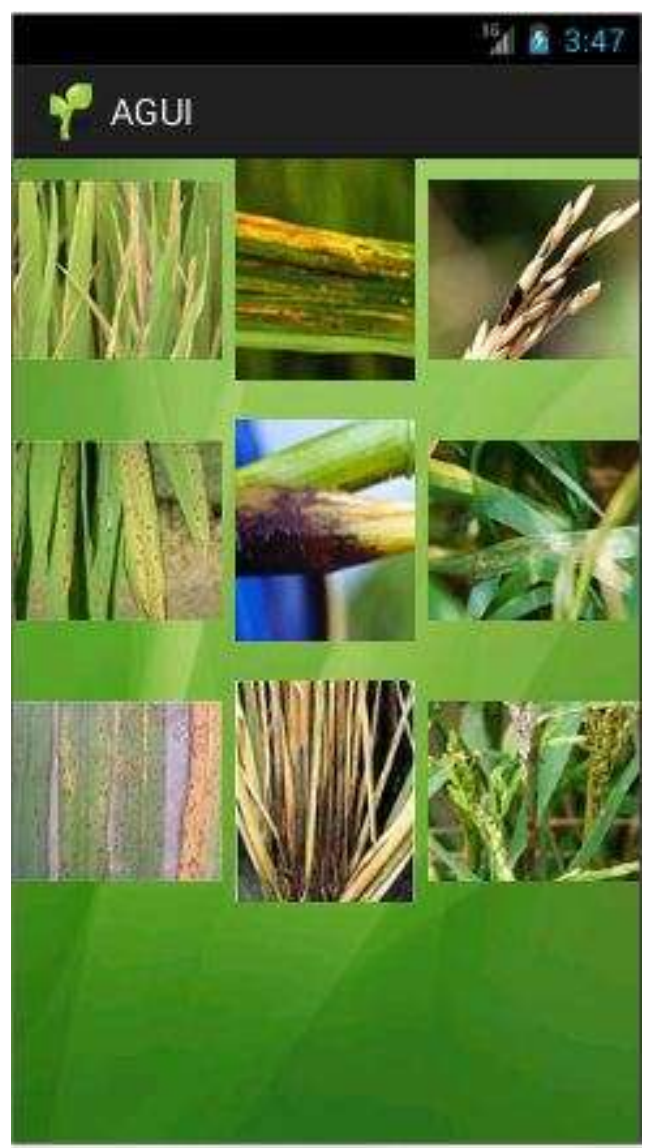

Fig 11: Disease List for Rice

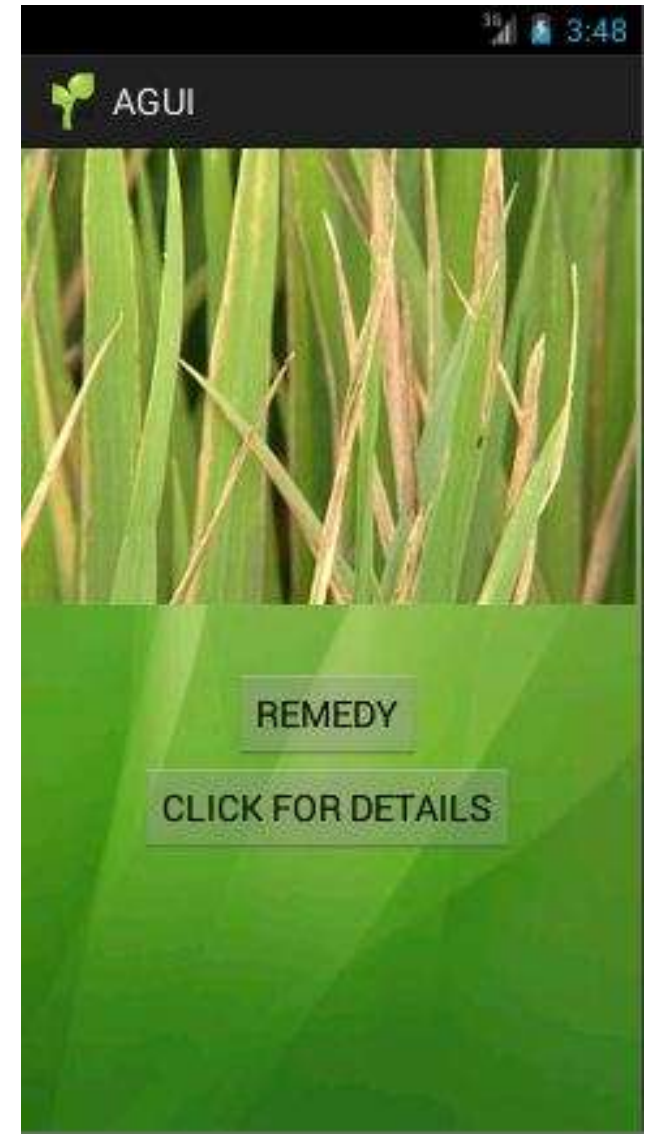

Fig 12: Bacterial Blight confirmation

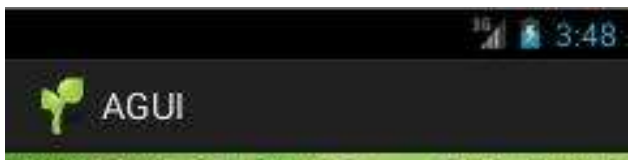

Why and Where it Decurif? The nisease is most likely to develop in areats that have-weeds and stubbles of infected plants. It pan cscur in both tropical and temperate envirohinents. particularly in irrigated and fain fed lowland areas. Ingeneral the disease favors: temperatures at $25-34^{\circ} \mathrm{C}$. With relative humidity above 70 \% it is commonly observed when strong winds and continuous heayy rains occur allowing the discase-eausing bacteria to easily spread through ooze droplets on lesiens of infected planis. Bacterial biloht can besevere in susceptible fice varieties under high nitrogen fertilization. How to identifym on seedings, infected leaves tum grayish green and roll $\mathrm{up}$. As the disease progresses, the leaves turn yellow to strav-colored and wilt, leading whole seedlings to diny up and die.

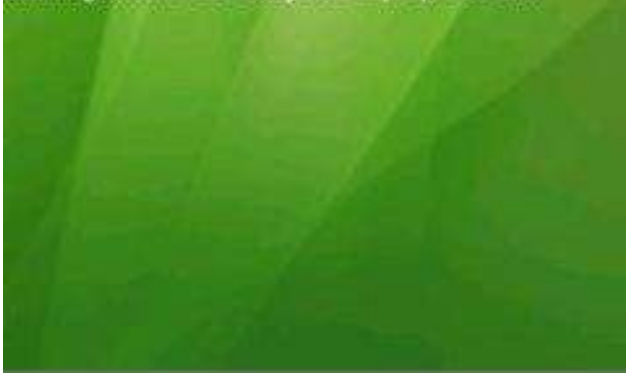

Fig 13: Details of Bacterial Blight 


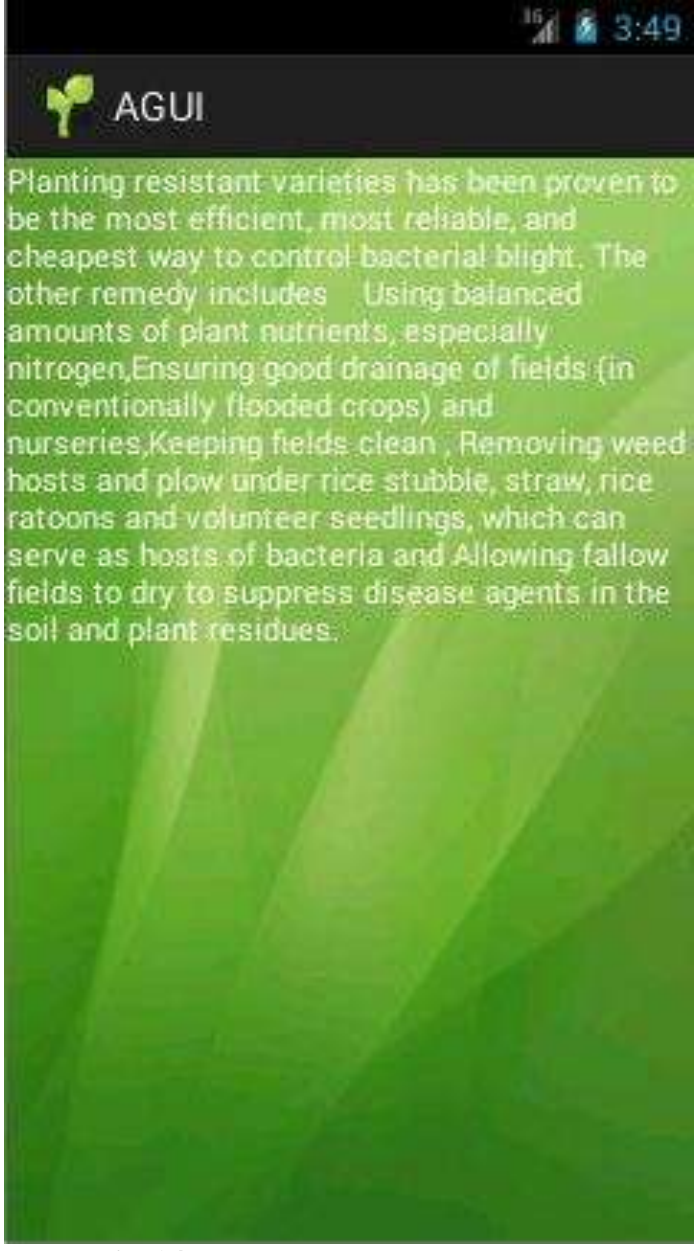

Fig 14: Remedy for Bacterial Blight

\section{CONCLUSION AND SCOPE}

Taking the resource constraint into consideration we have developed an android application for the farmers which will present the basic crops cultivated in India and its corresponding diseases in a graphical view to the farmers. This application provides the basic local information about each crop and also suggests the remedy information to the farmer for individual diseases. All the information and the remedy for the different crop have been taken from different agricultural departments.

The scope of this application is that it can be directly connected to the corresponding agricultural department by server implantation. By introducing this facility the farmer can connect to the agricultural department and can get information regarding the crop, diseases and the remedies as well directly from the agricultural help desk.

\section{ACKNOWLEDGEMENT}

We would like to thank our parents and colleagues for their inspiration for the acceleration during the work. We also like to extend our heartfelt thanks and immense gratitude to everyone from our institute side whose help and expertise advice greatly assist during the course of work.

\section{REFERENCES}

[1] Felker, D. \& Dobbs, J. (2011). Android Application Development for Dummies, Indianapolis, Indiana: Wiley Publishing, Inc.

[2] Open Handset

Alliance, http://www.openhandsetalliance.com

[3] Walisadeera, A. I., Wikramanayake, G. N., \&Ginige, A. (2013). An ontological approach to meet information needs of farmers in Sri Lanka. In Computational Science and Its Applications-ICCSA 2013 (pp. 228-240). Springer Berlin Heidelberg.

[4] Narula, S. A., \&Nainwal, N. (2010). ICTs and Agricultural Supply Chains-Opportunities and Strategies for Successful Implementation Information Technology in Developing Countries. A Newsletter of the International Federation for Information Processing (IFIP) Working Group, 9, 24-28.

[5] Ma, L., Gu, L., \& Wang, J. (2014). Research and Development of Mobile Application for Android Platform. International Journal of Multimedia and Ubiquitous Engineering, 9(4), 187-198.

[6] Bhati, S., Sharma, S., \& Singh, K. Review On Google Android a Mobile Platform. IOSR Journal of Computer Engineering (IOSR-JCE) e-ISSN, 2278-0661.

[7] https://developer.android.com/index.html

\section{BIOGRAPHIES}
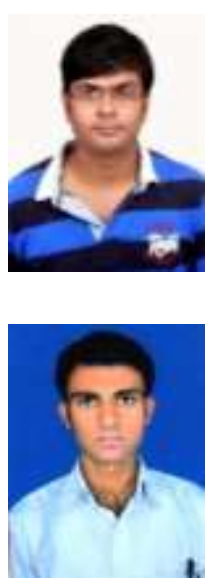

Mr Amrutanshu Panigrahi is currently acting as Asst Prof in NSIT Bihta Patna. His research area includes Wireless Sensor Network, Operating System, Mobile computing, Real Time System, Network Security and Image Processing.

Md Mohtab Alam is currently acting as Asst Prof in NSIT Bihta, Patna. His research are includes Wireless and Mobile Computing, IDS, Information Security. 